\title{
Danza en la Escuela Víctor Jara: un análisis situado desde la educación popular, la
} interculturalidad crítica y los estudios de danzas

Dance at the Víctor Jara School: an analysis situated from Popular Education, critical interculturality and dance studies

\section{Paulina González ${ }^{1}$}

INDEPENDIENTE

\section{Resumen}

En este artículo se presenta un análisis teórico decolonial situado en la experiencia particular del Taller Danza Grandes de la Escuela Víctor Jara, a partir de la vinculación entre esta práctica y la tríada conceptual de educación popular, interculturalidad crítica y danzas. Esta propuesta se levanta en miras de facilitar perspectivas y materiales más allá de las concepciones hegemónicas de la praxis de la educación y la danza en contextos interculturales. Dicho ejercicio es llevado a cabo con el objetivo de analizar la interacción entre la práctica del Taller Danza Grandes y la tríada conceptual propuesta, abordándolo desde la metodología de la investigación-acción participativa para visualizar tanto las vinculaciones efectivas como las tensiones y tareas aún por cumplir. Pretendemos con ello aportar insumos a actuales y futuros ejercicios de pedagogía crítica en danzas que se desarrollen en contextos de realidad migratoria latinoamericana.

Palabras clave. Danzas; Educación popular; Interculturalidad crítica; Decolonialidad.

\begin{abstract}
This article presents a decolonial theoretical situated analysis in the particular experience of Taller Danza Grandes of the Escuela Víctor Jara, based on the relation between this practice and the conceptual triad of popular education, critical interculturality and dances. This proposal is raised to offer a view that can issue perspectives and materials further beyond the hegemonic conceptions of the praxis of education and dance in intercultural contexts. This exercise is carried out with the aim of analyzing the interaction between the practice of the Taller Danza Grandes and the proposed conceptual triad, approaching it from the methodology of participatory action research to visualize both effective links, tensions and tasks yet to be fulfilled. With this, we intend to insumate current and future exercises of critical pedagogy in dances that develop in contexts of Latin American migratory reality.
\end{abstract}

Key words. Dances; Popular education; Critical interculturality; Decoloniality.

\footnotetext{
${ }^{1}$ Pedagoga en Danza- Universidad ARCIS, se desempeña como docente, investigadora y creadora desde el ámbito de las danzas latinoamericanas y contemporáneas. Mail: pauli.paulinagonzalez@gmail.com
} 
GONZÁLEZ PAULINA - Danza en la Escuela Víctor Jara: un análisis situado desde la Educación Popular, la interculturalidad crítica y los estudios de danzas

\section{Introducción. Conceptualizaciones y antecedentes claves para el análisis: la Escuela Víctor Jara y el Taller Danza Grandes}

La Escuela Víctor Jara es un proyecto colectivo y autónomo que se desarrolló entre los años 2009 y 2016 con el fin de facilitar un espacio político-educativo para la integración entre las niñas, los niños $^{2}$ y los jóvenes (entre 4 y 18 años) de distintas nacionalidades y realidades que habitan el Barrio Yungay, comuna de Santiago, ciudad de Santiago de Chile. ${ }^{3}$

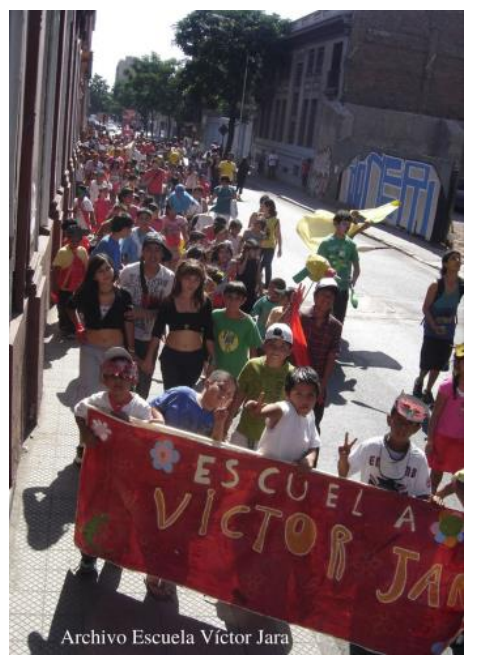

Dicho espacio utilizó el arte como una herramienta y se desarrolló en dos modalidades: talleres regulares durante el año, los días sábados generalmente, y las escuelas intensivas, organizadas durante las vacaciones de invierno y verano de los estudiantes en etapa escolar. La escuela de verano se convirtió en el espacio intensivo más largo (todo el mes de enero) y con la mayor presencia de niñas, niños y jóvenes (entre 100 y 300, dependiendo del año). Resulta coherente, entonces, señalar que en esta instancia de gran convocatoria era donde se realizaba la mayor cantidad de talleres y, dentro de ellos, el Taller Danza Grandes.

El Taller Danza Grandes incorporó a jóvenes desde los 9 años en adelante, provenientes de diversos países, sobre todo sudamericanos, como Chile, Perú, Colombia, Bolivia y Ecuador. En el caso de las escuelas intensivas de verano, este espacio educativo se impartía de lunes a viernes, con clases de una hora y media de duración, completando un total de veinte clases aproximadamente, con una participación de 12 a 40 jóvenes, dependiendo del año de realización.

Para el desarrollo de este artículo, nos focalizaremos en el Taller Danza Grandes de las escuelas intensivas de verano, en particular entre los años 2011 y 2014, periodo donde sucedieron hitos pedagógicos sustanciales para la práctica político-educativa del proyecto. Se analizará, de forma vinculante, el ejercicio del Taller Danza Grandes con el proyecto de la Escuela Víctor Jara como un ir y venir que nos permita comprender de manera integral el foco de nuestra observación.

Este ejercicio se llevará a cabo a partir del análisis de la relación de la experiencia antes mencionada con las concepciones de la educación popular, la interculturalidad crítica y las danzas. Este acercamiento teórico se abordar desde la metodología de investigación-acción participativa, considerando que quien escribe participó de forma activa en la construcción de la

\footnotetext{
${ }^{2}$ Para fines del artículo, ocuparemos un lenguaje inclusivo binario para hablar de las y los jóvenes, niñas, niños, etc. Sin embargo, el planteamiento basal y crítico desde el cual nos proponemos abordar el género se vería mejor reflejado con el uso de la " $x$ " para materializar, de forma concreta, la apuesta de desbinarizar tanto el lenguaje como las danzas. Esperamos prontamente que tales posibilidades puedan ser plasmadas en artículos académicos.

${ }^{3}$ Para más información véase: https://www.youtube.com/watch?v=kNpj2UiiTyk.
} 
práctica educativo-política de la Escuela Víctor Jara. A partir de ello, resulta coherente posicionarse conceptual y metodológicamente desde ese lugar, lo que permite e incita a involucrarse de manera participativa a la vez que propicia el uso de la teoría crítica. Se refuerza así la propuesta de relevar conocimientos desde fuera de la concepción hegemónica de la praxis educativa en danzas desarrollada en contextos interculturales y su respectiva ideología y visión de mundo.

Abordaremos tal objetivo observando la experiencia situada, practicada y vivida de la Escuela Víctor Jara y, en particular, del Taller Danza Grandes, en interacción con la mirada de la educación popular a partir de Freire $(13,14)$, la interculturalidad crítica desde Viaña, Tapia y Walsh (76) y Tijoux (5), y las danzas en la perspectiva de Arce et al. (61), Sigl y Mendoza (786), así como del Colectivo Miradas Críticas del Territorio desde el Feminismo (7). Comenzaremos por cimentar el universo conceptual que nos permite situar este trabajo, definiendo a qué nos referimos con educación popular, interculturalidad crítica y danzas, para luego proponer dos ejes de análisis de la experiencia del Taller Danza Grandes: el primero es de la decolonialidad como horizonte y praxis, y el segundo el de las tensiones y posibilidades desde lo tradicional, lo actual y el rito como constructo móvil. Finalizaremos plasmando las relaciones efectivas logradas y algunas de las tareas que quedan por cumplir, sobre todo desde la perspectiva de género, identidad y racialización.

\section{Educación popular}

Podríamos describir la educación popular como "[e]l conjunto de las prácticas educativas realizadas por y con los sectores populares, dentro de una perspectiva política de cambio social" (Preiswerk 31). En este postulado leemos una pedagogía que se propone como ejercicio políticoeducativo en miras de una emancipación colectiva, la cual entendemos como un actuar en oposición a las pedagogías que trabajan para el sistema hegemónico imperante. Este planteamiento crítico y basal en la visión de la educación popular se encuentra directamente vinculado con una crítica mayor al funcionamiento de las estructuras del actual sistema "colonialcapitalístico", como diría Suely Rolnik (11), que nos invita a hacer una lectura entramada de las opresiones sistémicas vigentes. Si esta mirada la situamos en el análisis de una práctica educativa con jóvenes, no puede sino evidenciar y conflictuar el componente adultocéntrico (Duarte 18) como parte central de su crítica.

Sin embargo, dichas ideas no solo cuestionan la forma en que funciona la escuela formal en el sistema vigente, sino, también, tensionan e invitan a cierta manera de actuar acompañando, reforzando y consolidando horizontes posibles a partir de experiencias realizadas fuera del marco de la educación formal, con proyectos comunitarios y autónomos, tales como la Escuela Víctor Jara. El deseo, entonces, de abrir brechas hacia la emancipación colectiva nos lleva a relevar la noción de autonomía, muy en la línea del feminismo comunitario (Gutiérrez, 96; Guzmán, 3) y las ideas de autogobernanza, entendidas desde las pedagogías de las comunidades zapatistas (Baronnet 64). Esto nos empuja, a su vez, a posicionar la práctica dialógica como la sostiene Paulo Freire (72), entendiendo el diálogo como un ejercicio necesario y constante que debe ser realizado por y para nosotras y nosotros. Con ello se busca conocer, saber más en colectivo, fisurando las nociones convencionales de los educadores y los educandos. La intención es posicionar lo colectivo desde el entendimiento de las infancias y juventudes como agentes activos 
GONZÁLEZ PAULINA - Danza en la Escuela Víctor Jara: un análisis situado desde la Educación Popular, la interculturalidad crítica y los estudios de danzas

de los procesos de transformación social, política y cultural, en vínculo con los postulados de autonomía y autogobernanza, como un tejido de principios que se entrelazan en dirección a la emancipación.

\section{Interculturalidad crítica}

Al igual que el perfil cuestionador de la conceptualización educativa asumida más arriba, el componente crítico de esta perspectiva nos invita a diferenciar la interculturalidad crítica de la interculturalidad funcional. Sobre ello, Viaña, Tapia y Walsh plantean:

La distinción entre una interculturalidad que es funcional al sistema dominante, y otra concebida como proyecto político de descolonización, transformación y creación [...] la educación intercultural en sí sólo tendrá significación, impacto y valor cuando esté asumida de manera crítica, como acto pedagógico-político que procura intervenir en la refundación de la sociedad, como decía Paulo Freire (2004: 18) y, por ende, en la refundación de sus estructuras que racializan, inferiorizan y deshumanizan (76).

Este planteamiento sobre la interacción entre diversas culturas, releva el hecho de que estas interactúan inevitablemente dentro de un sistema compuesto por relaciones de poder y por una simultaneidad de opresiones que comprenden las de clase, raza, género, edad, etc. Dichos elementos son fundamentales para una comprensión crítica de este diálogo y para emprender una lectura en clave decolonial (Viaña, Tapia y Walsh 76; Lander y Castro-Gómez 11; MaldonadoTorres 127; Quijano 203)

Habiendo mencionado esto, y en miras de situar aún más el contexto para el análisis, proponemos vincular las ideas de interculturalidad crítica con la concepción de migrante distinguiéndola de extranjero, desde la perspectiva de Tijoux:

No es una situación nueva, pues siempre han llegado inmigrantes en distintos momentos de la historia, por grupos, huyendo también o buscando trabajo. Solo que hoy el número aumenta y sus actores no son tan bienvenidos como los del siglo XIX, por ejemplo, debido a su color, su condición, su nacionalidad y su género. 
Principalmente vienen de Perú, Bolivia, Ecuador, República Dominicana, Colombia y Haití, orígenes que los cataloga para que la sociedad chilena los perciba negativamente como “inmigrantes”, logrando que el concepto de inmigración se vacíe de su sentido al señalarlos como tales, mientras que lo extranjero será el concepto que nombrará a quienes serán bien o medianamente bien acogidos, al menos hasta ahora y según el modo en que siga dándose la dinámica migratoria en el mundo (5).

De esta manera, vemos la relevancia de proponer un universo conceptual que no solo reconozca la existencia de múltiples culturas en diálogo y la condición de migración, sino que se posicione desde una visión crítica que invite a otra forma de actuar, como señalan Viaña, Tapia y Walsh, una que: "Apuntala y requiere la transformación de las estructuras, instituciones y relaciones sociales, y la construcción de condiciones de estar, ser, pensar, conocer, aprender, sentir y vivir distintas" (78)

\section{Danzas}

En este artículo nos proponemos mirar las danzas desde la diversidad y un abordaje en clave decolonial. Por ello se explicita en plural la idea de la danza desde una intención política de visibilización: "Diversidad que nos presenta la 's' para la danza, las danzas, como primer ejercicio de inclusión histórica de otras y otros que danzan en plural y en reclamo sobre nuestros imaginarios conquistados por Occidente y las manifestaciones artísticas" (Arce et al. 61). Con esta opción nos proponemos relevar lo diverso de las danzas en miras de tensionar los límites eurocéntricos que han definido qué es o no danza, qué cuerpos pueden o no bailar y qué danzas merecen o no ser estudiadas en la concepción más formal de la palabra.

En el momento de situar geopolíticamente estas danzas, nos encontramos con la noción de estas como ritos. Ritos, por una parte, asociados al calendario agrícola de diversos pueblos del Abya Yala (Sigl y Mendoza 786), como es el caso, por ejemplo, del Pachallampe, que se danza durante la siembra de la papa en las localidades altiplánicas de la Región de Arica y Parinacota (Lanka y Morales). Por otro lado, los ritos también pueden ser vistos como representaciones danzadas de tradiciones, como es el caso de la danza del tinku, representación del ritual del mismo nombre, festejado los 3 de Mayo en la localidad de Macha, Potosí, con el que se busca hacer una ofrenda a la Pachamama (El Rincón Boliviano).

Continuando con esta apuesta decolonial, entendemos la colonización como un periodo constituido por un conjunto de procesos (Lugones 88) marcados por el saqueo de la naturaleza, el genocidio de los pueblos originarios del Abya Yala y la entrada de personas en situación de esclavitud para explotar tales tierras. Con estos antecedentes, proponemos entender las danzas, estas "otras" danzas que surgen en este territorio geopolíticamente común, ya sea previas o posteriores a este proceso, como un acto de resistencia. Si desde la perspectiva del rito ponemos en tensión la "colonialidad del saber" (Lander y Castro-Gómez 11) visibilizando otras danzas y 
GONZÁLEZ PAULINA - Danza en la Escuela Víctor Jara: un análisis situado desde la Educación Popular, la interculturalidad crítica y los estudios de danzas

formas de construir los saberes colectivos de estos territorios, con esta mirada de resistencia proponemos disputarle terreno a la "colonialidad del ser" (Maldonado-Torres 127), que fervientemente busca despojar a las personas de su condición humana, objetualizándolas y transformándolas en mercancía (Arce et al. 76).

Un ejemplo de esta resistencia, de esta disputa, es la capoeira: "El extremo sometimiento físico, psicológico y emocional, sitúa al individuo a tal nivel de deshumanización que la práctica de la capoeira reincorpora al cuerpo del sujeto a una dinámica extra esclavista necesaria para la sobrevivencia en este ambiente hostil" (Arce et al. 76). Prácticas como estas fueron desarrollas por afrodescendientes en situación de esclavitud o a raíz de estos procesos, con estrategias como adecuar las celebraciones de sus deidades al calendario de celebración católica (Bastide 145), entre otras. Dichas estrategias de resistencia también fueron sostenidas, aunque de formas distintas, por los pueblos originarios de Abya Yala: "La resistencia como propuesta más actual [...] como un acto de resistir identidades, racismos, marginaciones y problemáticas que emergen de la migración latinoamericana indígena y afrodescendiente a Chile en los últimos años, contexto en el cual se desarrolla el Taller de Danza Grandes” (González 11)

Para seguir sumando capas a la compresión de las danzas, proponemos, también, verlas como expresión sensoperceptiva, donde la experiencia en sí misma, lo biográfico, el habitar simplemente el movimiento, componen un elemento esencial del acto de danzar:

Memorias, reflexiones y sentires, impreso en nuestros cuerpos nos devela el movimiento en las prácticas corporales. Una suerte de archivo arqueológico vivo, en constante cambio, que se permeabiliza por una red de cuerpos sensibles, que han situado su tránsito en el mundo, en un quehacer. Hábito, en cuerpos en movimientos que resignifican su movilidad, en comprensión y relación a un habitar, de conexiones libres y complejas (Campos en Arce et al. 58).

Esta corporeización biográfica y casi intrínseca de las danzas es tan diversa como sus contextos de inscripción y los cuerpos que las practican. Por esta razón nos parece relevante sumarla a la concepción de danzas como una forma de abrir espacios a las particularidades de los universos personales y colectivos que abordaremos.

Tras haber englobado el marco conceptual de las danzas desde múltiples aristas de lectura, resulta necesario señalar, quizás, una obviedad: es imposible hablar de danzas sin hablar de cuerpos. El cuerpo es quien encarna todas estas formas de entender las danzas en plural, como rito, como resistencia, como acto sensoperceptivo. En la medida en que vamos entretejiendo tales ideas desde una mirada decolonial, necesitamos situar el cuerpo como un espacio de disputa donde dialogan no solo las danzas, sino las ideas propuestas más arriba de educación popular e interculturalidad crítica. 
Al respecto, es necesario visibilizar e identificar cómo es que en ese cuerpo operan una simultaneidad de opresiones de raza, clase, género, edad. Al hacerlo, sintonizamos con las ideas de las feministas comunitarias, quienes nos invitan a entender el cuerpo como territorio:

Pensamos el cuerpo como nuestro primer territorio y al territorio lo reconocemos en nuestros cuerpos: cuando se violentan los lugares que habitamos se afectan nuestros cuerpos, cuando se afectan nuestros cuerpos se violentan los lugares que habitamos. Estas enseñanzas nos las mostraron compañeras de muchas partes de Latinoamérica sobre todo del mundo rural e indígena (Colectivo Miradas Críticas del Territorio desde el Feminismo 7).

\section{La decolonialidad como horizonte y praxis}

En este primer eje de análisis, nos encontramos con la necesidad, tanto teórica como práctica, de situar con fuerza la perspectiva decolonial en cuanto horizonte hacia el cual seguir caminando y practicando de forma colectiva. Esta perspectiva nos invita a cuestionar, en términos estructurales, ideas como lo binario y a analizar la concepción mente-cuerpo y las concepciones en torno al género (hombre-mujer). Por otro lado, también nos empuja a situarnos geopolíticamente dentro del Sur global, que es donde se desarrolla esta práctica en cuestión. Si bien la Escuela Víctor Jara no se declaró explícitamente como decolonial durante sus años de ejecución, el presente análisis y su posicionamiento educativo y político nos permiten situarla desde ahí, tras observar su práctica educativa como una búsqueda constante, con base en el ensayo y el error, por fisurar los estragos del actual sistema colonial capitalístico en nuestras vidas.

Al entender el proyecto educativo Escuela Víctor Jara como un planteamiento contextual, paralelo y crítico podemos sostener la idea de un espacio en el que se practicó y se proyectó una apuesta decolonial. Fue contextual en la medida en que se construyó a sí mismo poniendo a quienes participaban en él en el centro de la lectura de los diagnósticos y las problemáticas y, con ello, de las posibles soluciones y metodologías a aplicar desde un ejercicio de emancipación colectiva que situó a sus integrantes como agentes de cambio y como fuente de creación de conocimiento. Fue paralelo en cuanto se propuso como un ejercicio fuera de la estructura de la escuela formal, a partir de la construcción de metodologías, contenidos y prácticas relacionales, que se desarrollaron como un camino alternativo al proyecto de escuela formal chilena, en la línea de los principios de autogobernanza educativa, como señala Baronnet: 
GONZÁLEZ PAULINA - Danza en la Escuela Víctor Jara: un análisis situado desde la Educación Popular, la interculturalidad crítica y los estudios de danzas

Desde allí, la escuela se vuelve el lugar de un aprendizaje culturalmente situado, pertinente y descolonizador en la medida en que son los autónomos quienes se encargan de determinar lo que es prioritario enseñar a las nuevas generaciones. Este trabajo de deliberación y negociación interna por medio de prácticas de asamblea es parte del proceso de toma de decisión sobre acciones de autogobierno educativo (64).

En acuerdo con esta idea, abordamos el aspecto crítico desde la oposición al funcionamiento actual del sistema colonial capitalístico y de su visión de los procesos educativos, instalando las artes como la herramienta central para el abordaje de las problemáticas estructurales que esta postura identifica y rompiendo su histórico rol en la escuela formal como recreación o adorno. Con ello tensiononamos la estructura misma de la noción de danzas y de qué danzas "vale la pena" enseñar en una escuela.

Es así como el posicionamiento crítico aparece como un elemento central y transversal bajo el cual se mira no solo el aparataje sistémico estructural y colonialista que hemos mencionado, sino también uno que se propone criticar las prácticas micropolíticas y cotidianas que debemos desbaratar para lograr encarnar estos otros horizontes posibles. Como dice Rolnik:

Cuando esto sucede, el personaje del opresor, su compañero de escena, se queda hablando solo y la escena ya no tiene cómo seguir existiendo. ¿No será precisamente esta operación de insurrección micropolítica lo que viene siendo introducido por los movimientos actuales antes mencionados $[\ldots]$ ? (123).

Estos parámetros deben ser comprendidos, además, en relación con el momento político en el cual el Taller Danza Grandes nace y se consolida. La fuerte movilización estudiantil sucedida en 2011 en Chile, que puso en la palestra la idea de una educación emancipadora y no lucrativa, fortaleció profundamente la decisión de la Escuela Víctor Jara de situarse fuera de la escuela formal y proponer procesos de autoeducación por y para nosotras y nosotros. En ello vemos también una fuerte relación de incidencia entre lo macro-micropolítico, en la forma de hacer y entender lo político dentro de lo pedagógico y en cómo permea el posicionamiento de la Escuela frente al manejo de la interculturalidad y lo particular disciplinar de las danzas. Estos procesos macropolíticos afirman el ánimo y la necesidad de levantar proyectos transformadores y colectivos. García releva: 
Sólo a partir de procesos educativos es posible transformar realidades, derribar ídolos epistémicos, romper estructuras de poder, etc. Sin embargo, como nos lo advierte Freire (1967), no se trata de cualquier educación; son necesarios proyectos educativos o pedagogías liberadoras que marchen a contracorriente de las políticas estatales dirigidas a la domesticación de la mentalidad de los pueblos. Es la educación como diálogo político (Freire, 1972) la que nos ayuda a enfrentar con éxito el discurso educativo técnico, desmovilizador y perennemente colonial que promueven los gobiernos en América Latina (79).

Dentro del intencionado actuar micropolítico de la Escuela Víctor Jara, se abre camino una educación situada y autoejercida, con una mirada desde la interculturalidad crítica aplicada como ejercicio no solo desde la oposición, sino de resistencia activa desde y con las juventudes migrantes y locales que componen el taller. Junto con ellas y ellos se llevó la concepción de danzas a un lugar plural y dialógico, donde el cuerpo-biográfico, atravesado por múltiples opresiones, es puesto en el centro del ejercicio político-pedagógico decolonial.

\section{Estructura organizacional del Taller Danza Grandes entre 2011 y 2014}

Proponemos, entonces, analizar, desde una mirada decolonial, la estructura bajo la cual se organizó el Taller Danza Grandes, para observar, a partir de esta configuración, una propuesta educativa situada, que utiliza las danzas como una herramienta de compartición, ${ }^{5}$ en relación constante con las necesidades de los cuerpos-biografías que constituyen el espacio taller.

Un elemento inicial a contemplar en este espacio, es el constante proceso de diagnóstico y evaluación que fueron realizando las educadoras del taller, el resto de los educadores de la Escuela y las y los jóvenes que participaban a partir de la observación de las metodologías, el ambiente general de la Escuela y otras variables que incidían y determinaban las directrices de cómo plantear tanto la Escuela en general como el Taller Danza Grandes en particular. Esto lo subrayamos puesto que:

5 “Como lo dirían las, los zapatistas, la compartición es compartir el ser, hacer y estar en el mundo desde el diálogo horizontal, la humildad, la creatividad y las ganas de crecer y resonar juntas" (Colectivo Miradas Críticas del Territorio desde el Feminismo 23). 
GONZÁLEZ PAULINA - Danza en la Escuela Víctor Jara: un análisis situado desde la Educación Popular, la interculturalidad crítica y los estudios de danzas

Resulta relevante mencionarlo pensando en que dichas evaluaciones y diagnósticos permitieron, durante todos los años de existencia del proyecto, reafirmar la necesidad de un Taller de Danza Grandes que funcionara como herramienta para abordar problemáticas de identidad, autoestima, creatividad y buen trato, de forma motivante y colectiva. Estas problemáticas identificadas se transformaron entonces en los objetivos pedagógicos trabajados durante los años 2011 a 2014 en el Taller (González $51)$.

Esta reafirmación constante se instaló por la necesidad de generar un espacio motivante para trabajar los objetivos propuestos con base en los intereses y las necesidades colectivas y personales de las y los jóvenes del Taller, entendiendo por jóvenes tanto a las educadoras (todas menores de 25 años) y los participantes del barrio. Se construyó así un conocimiento no a partir de los arquetipos de nacionalidad, género, raza, etc., sino a través de la participación activa y propositiva de las biografías y las corporalidades que componían el espacio educativo.

Estos elementos creativos y particulares son los que distinguían al Taller Danza Grandes de los otros espacios de danzas del proyecto. El Taller Danza Carnaval cumplía un rol de visibilización cultural e integración entre los y las participantes de la Escuela por medio del aprendizaje colectivo de las danzas y ritmos latinoamericanos. El Taller Danza Chicas y Chicos, por su parte, estaba enfocado en niñas y niños de 4 a 8 años, donde si bien se planteaban objetivos similares, la motivación, los tiempos y, por ende, las metodologías de trabajo en ese bloque etario son menos disciplinares y más interdisciplinares, como era el caso también del Taller de Cortometraje, por ejemplo. Estas diferencias se traducen en objetivos y/o metodologías distintas y, por ende, en talleres con enfoques diferentes. En el Taller Danza Grandes, en ese sentido, se trabajaba desde las capacidades creativas personales y colectivas del grupo particular de jóvenes que lo habitaban.

Habiendo aclarado esto, pasamos a ejemplificar el funcionamiento de la estructura y los objetivos trazados para el Taller Danza Grandes entre los años 2011 y 2014. Si bien se trabajaban los cuatro objetivos citados más arriba (identidad, autoestima, creatividad y buen trato), las dinámicas se focalizaron más intensamente sobre uno o dos de ellos, de acuerdo con las necesidades contextuales del periodo.

En el caso del Taller Danza Grandes de la Escuela de Verano 2011, este se desarrolló en una Escuela intensiva particularmente masiva, en la que participaron alrededor de 300 niñas, niños y jóvenes, lo que propició que se realizaran dos Talleres Danza Grandes de manera simultánea, ambos con dos objetivos centrales: el buen trato (elemento consensuado como central por las y los educadores debido a la masividad) y el desarrollo de la creatividad. 
En 2012, a partir del proceso de fortalecimiento de las líneas pedagógicas de la Escuela facilitado por la comisión de autoeducación del proyecto, se decidió trabajar con objetivos transversales para todo el centro: "trabajar la violencia identificada en los procesos anteriores de forma positiva, por medio del desarrollo de las potenciales que dan los conceptos de identidad y autoestima" (González 53), lo que incluyó al Taller Danza Grandes de ese año.

En los años 2013 y 2014 se afinaron las ideas de trabajo con objetivos transversales, lo que indujo variaciones en las metodologías de cada uno de los talleres. Ello consolidó la política de la Escuela desde la noción de que las problemáticas surgidas e identificadas en los años anteriores eran estructuralmente las mismas, lo que llevó a plantear un trabajo sinérgico de los objetivos para "potenciar la autoestima e identidad tanto personal como colectiva a través del trabajo creativo y colectivo" (González, 53) en un ambiente de buen trato.

El Taller Danza Grandes se orientó, en particular, a reforzar el trabajo de identidad y pertenencia a ese espacio, configurado por y para quienes lo componían, desde la base de practicar las diferencias como un valor y aporte a la construcción de lo colectivo tanto del taller como de la Escuela. Con ello se buscaba incidir más allá del espacio educativo, hacia la realidad barrial, atravesada por discriminaciones y violencias asociadas a las realidades migratorias y su diálogo (y no diálogo) con lo local.

Al respecto, hacemos referencia a las posibilidades de transformación a través de las ideas de identidad que promueven las comunidades afrodiaspóricas de Nariño, Colombia, en las palabras de Jorge García Rincón:

La identidad, en este sentido, es un concepto político, esto es, un escenario de reconstrucción de una subjetividad colectiva afrodiaspórica que ha sido adormecida por la aplicación de nuevas estrategias de dispersión tales como el multiculturalismo de Estado, el desplazamiento forzado, o algunas ya mencionadas como la institucionalización y las políticas de educación estandarizadas, etc., todas ellas nuevas estrategias de dominación en la prolongación del sistema-mundo moderno colonial. En consecuencia, la identidad como un escenario de pensamiento y como construcción política desde un lugar de enunciación específico de la sociedad, es decir, como superación de la concepción folclorista que tiene el Estado y el país en general sobre la cultura afro (76). 
GONZÁLEZ PAULINA - Danza en la Escuela Víctor Jara: un análisis situado desde la Educación Popular, la interculturalidad crítica y los estudios de danzas

Vemos ejemplificada, en la configuración móvil del programa del Taller, como diría Freire (78), la intención de posicionarse mirando hacia un horizonte decolonial, en la medida en que nos situamos a nosotras y nosotros como fuente de conocimiento. A partir de una construcción dialógica, este programa se esmeraba en instalar una pedagogía crítica en danzas que permitiera reelaborar prácticas y levantar un espacio educativo propio, con perspectiva geopolítica y en miras de la emancipación no solo simbólica, sino también micropolítica, de las realidades de las y los jóvenes migrantes y chilenos del Barrio Yungay que constituían el Taller.

\section{Tensiones y posibilidades desde lo tradicional, lo actual y el rito como constructo móvil}

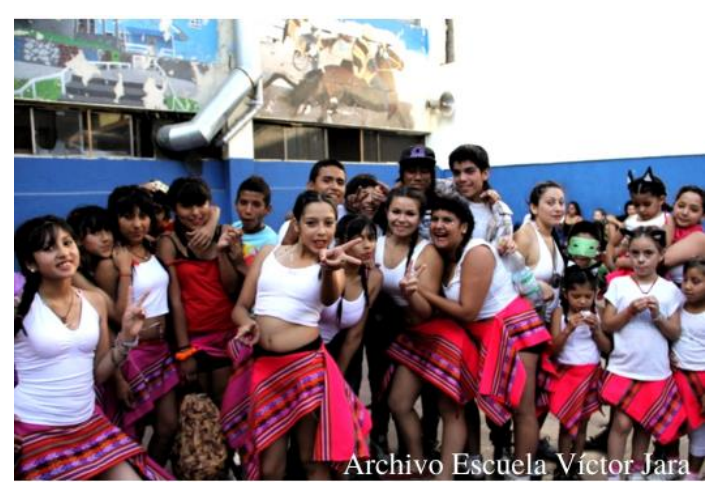

Junto con la observación de la experiencia situada del Taller Danza Grandes desde las nociones de educación popular, interculturalidad crítica y danzas, proponemos, como segundo eje de análisis, indagar tanto en las posibilidades como en las tensiones que se pusieron en juego en este proyecto en relación con las ideas de tradición, nuevas construcciones y el rol del rito en esta práctica educativo-política.

Enmarcamos aquí la tradición en vínculo directo con lo dialógico, tanto desde la concepción de la educación popular y la apuesta freiriana, como del diálogo entre culturas a partir de la mirada de la interculturalidad crítica. Lo tradicional en las danzas y las prácticas en general del taller son entendidas como una configuración móvil que se encuentra en constante mutación, percepción muy conectada con las ideas sobre la identidad propuestas más arriba. Según Sigl y Mendoza:

Para llevar en alto esa "tradición" no sólo se conservan canciones, oraciones, ritos, adivinanzas y chistes sino también se re-interpreta y (re-)construye la historia propia, lo que ayuda a construir algo continuo, "natural" y/o sobreentendido que garantiza que los conocimientos transmitidos puedan aplicarse en el presente (218).

Si nos situamos desde esta concepción de tradición, nos permitimos abrir nuevos caminos de transformación y acción para relevar, releer y crear otras formas de enfrentar nuestra realidad geopolítica y llegar a fisurar el régimen colonial-capitalístico que opera micropolíticamente en nosotras y nosotros, facilitando el desarrollo de una praxis que permita acercarnos a los horizontes de emancipación colectiva que anhelamos.

Esto nos lleva a recontextualizar la idea de rito propuesta en las danzas, entendiendo el rito como un espacio cíclico donde una colectividad reitera una práctica con un sentido conjunto de identidad y pertenencia (Sigl y Mendoza,786), muy en sintonía con las posibilidades que se nos abren al entender la tradición como una configuración móvil y en constante recreación. Sin 
embargo, queremos enfatizar en que tal construcción móvil se ve necesaria, constante y críticamente tensionada por las ideas de apropiación cultural, estereotipación y asimilacionismo. ${ }^{6}$ No hay que olvidar que tales conocimientos provienen de realidades culturales constantemente invisibilizadas o transformadas en mercancía por los constructos hegemónicos. Frente a ello se propuso un ejercicio autocrítico, asumiendo que quienes componían como educadores la Escuela no eran migrantes ni racializados. Esto explica el llamado a mantener una actitud alerta en cuanto a las prácticas sistémicas racistas y coloniales que pueden operar a pesar de nosotros, pero en nosotras, conscientes siempre de que "obviar las historias también es marginar" (González 63).

Entre estas tensiones se construyó el Taller Danza Grandes desde el desafío de facilitar un espacio que permitiera dialogar a todas las biografías y corporalidades que lo componían desde la concepción de tradición móvil y situada, conformada a partir de lo que se quiere rescatar, transformar y crear. Ello de acuerdo con las necesidades de las y los jóvenes del taller y no desde el estereotipo de cuáles debieran o no ser sus intereses según el país de origen, la edad, el género, etc. Aludimos principalmente al estereotipo comúnmente impuesto a la población afrodescendiente de que solo por serlo le interesa ciertas danzas, lo que implica subliminalmente una fuerte sexualización hacia sus cuerpos.

En este deseo de particularizar y contextualizar sin caer en la estereotipación, recibimos como una influencia importante los procesos educativos zapatistas, según la mirada de Bruno Baronnet:

En vez de imponer definiciones externas de los contenidos culturales, se vuelve necesario promover las condiciones para el trabajo educativo autónomo que puedan asegurar la inclusión selectiva de la propia historia y de los propios recursos culturales (Rockwell 2011: 100). Este tipo de proyecto implica un trabajo considerable, con el fin de transformar las maneras de representar, compartir y crear el tipo de conocimiento necesario para la lucha continua (60).

El desafío, en el taller, fue el de construir un espacio lejos de estas estereotipaciones y situado según las necesidades dialogantes y móviles de estas biografías-corporalidades. Se implementaron así metodologías que hicieran aparecer estos otros conocimientos que muchas

\footnotetext{
${ }^{6}$ Entendemos el concepto de asimilacionismo como la expectativa y la intención de que quienes son considerados pertenecientes a una cultura minoritaria adopten como propia la cultura hegemónica o la que es considerada mayoritaria. Nohl (2014) sostiene que, en sociedades que se conciben a sí mismas como vinculadas con una única cultura nacional, las minorías irritan y una forma de enfrentarlas es implementando medidas políticas para su asimilación (Beniscelli, Riedemann y Stang 399).
} 
GONZÁLEZ PAULINA • Danza en la Escuela Víctor Jara: un análisis situado desde la Educación Popular, la interculturalidad crítica y los estudios de danzas

veces no tienen cabida en la escuela formal y su ideología asimilacionista, buscando así consolidar un espacio diverso, heterogéneo, vivo, afectivo, móvil, en tensión, crítico y propio.

\section{Taller Danza Grandes 2013: una experiencia en tensión}

En miras de seguir aterrizando estas posibilidades y tensiones en la experiencia aplicada del Taller Danza Grandes realizaremos un análisis teórico del taller impartido en la escuela de verano 2013, pensando en ese curso como un hito pedagógico ejemplificador de tales posibilidades y tensiones.

Para entrar en ello, proponemos, primero, una contextualización del momento en el cual se configuró, planificó y ejecutó este taller por ser un antecedente relevante para comprender las decisiones en cuanto a programas y metodologías aplicadas en ese proceso específico. Durante ese periodo, hubo en Yungay muchos enfrentamientos entre jóvenes del barrio, en peleas callejeras en las que algunos jóvenes terminaron apuñalados, entre ellos estudiantes del taller.

A partir de esta problemática urgente se desarrolló el proceso de preparación colectiva de la escuela de verano por parte de las y los educadores. Con base en reflexiones colectivas, revisiones de las evaluaciones tanto de las escuelas de verano previas como del programa de talleres del segundo semestre de 2012, la escuela de verano de 2013 realizó un cuestionamiento colectivo sobre cómo relacionarse con la comunidad-barrio tanto en el espacio del taller, como en el proyecto de la Escuela. Esto confluyó en la intención de potenciar los objetivos de identidad y pertenencia como centrales para promover otras formas de relación, identificación y compañerismo.

Desde estos objetivos, el Taller Danza Grandes decidió trabajar la problemática de forma concreta: realizar un montaje a partir de dos movilidades del interés de los jóvenes en el que primero se instala una dinámica de pelea, para luego entrar en una fusión de lenguajes, que refuerza, desde el guión y la metodología, la colaboración como práctica relacional. Estas dos movilidades fueron denominadas como las y los michael jacksons, y las y los salseros. Las educadoras del taller propusieron esta estructura y guión como delimitante temática del trabajo, así como las dos movilidades bajo la influencia de los ritmos que a las y los estudiantes les habían entusiasmado durante los talleres del segundo semestre 2012 y con los cuales se les veía usualmente jugar en los recreos.

En cuanto a la co-creación, cada una y uno de los estudiantes elegía la movilidad sobre la cual trabajar de forma más intensiva y cada grupo coreografiaba a partir de los movimientos que las y los estudiantes iban proponiendo con el acompañamiento y la mediación de una educadora que facilitaba formas espaciales para la coreografía y otras herramientas de composición que fueran necesarias. Luego, esas mismas composiciones grupales se iban intercalando por sumatoria para configurar la parte fusionada de lenguajes: el momento coreográfico de la colaboración. 
En cuanto al trabajo metodológico, hacemos aquí un breve desglose:

1. A modo de inicio, se realizaba alguna dinámica rápida, lúdica y colectiva.

2. Durante el desarrollo de la clase se trabajaba sobre el montaje final, ya

fuera creando por grupos, ensayando los momentos ya creados u observando

videos de referencia para alimentar tales creaciones.

3. Un cierre, que variaba entre un masaje rápido en círculo o un momento

de baile libre con alguna música que ellos y ellas quisieran, donde solía

abundar la bachata (González 66).

Sirviéndonos de la idea de rito mencionada, podemos leer los espacios de inicio y cierre como rituales, al tratarse de una construcción cíclica reiterada que permite la identificación y la pertenencia al espacio del taller. Estos ritos fueron posibles gracias a los más generales de la Escuela, como el rito de inicio, llevado a cabo durante todas las mañanas de las escuelas intensivas de verano de 2010, 2011 y 2012, momento en que las y los participantes del proyecto realizaban un círculo y cantaban la canción de la Escuela, compuesta por las y los educadores del Taller de Música, que se renovaba cada año. Este acto colectivo derivó en otros más particulares y focalizados, como los mencionados más arriba, ritos intencionados desde la pertenencia al taller y por las posibilidades que ofrecen para fortalecer otras formas de relación, de cuidado propio y colectivo en un espacio de diversidad cultural, etaria y más.

Por otro lado, si bien la estructura de clase que hemos descrito resulta bastante genérica en cuanto a la forma de abordar metodológicamente las clases de danzas en espacios educativos formales, aquí enfatizamos una diferencia sustancial: el ambiente del taller se situaba al opuesto del propiciado desde la educación formal. Aquí el entorno era dinámico, la puerta quedaba abierta, las entradas y salidas a tomar agua o a buscar implementos se repetían, la sala era ruidosa y efusiva. Este ambiente da cuenta de una búsqueda propia, particular, distante de la clase directiva para coreografiar, por ejemplo, los trabajos danzados de Fiestas Patrias o de fechas como el 12 de octubre con su "celebración" del supuesto encuentro de dos mundos. En el Taller de Danza Grandes el ambiente de trabajo, el tratamiento de las danzas y, sobre todo, la validación de las particularidades situadas de las y los jóvenes participantes eran completamente distintos. 
GONZÁLEZ PAULINA - Danza en la Escuela Víctor Jara: un análisis situado desde la Educación Popular, la interculturalidad crítica y los estudios de danzas

Sostener esta atmósfera resultaba un desafío para las educadoras, quienes nos encontrábamos constantemente tensionadas (me incluyo entre ellas) en deconstruir también nuestra propia práctica pedagógica. Para conseguirlo fueron relevantes tanto la flexibilidad como el desarrollo de ciertas estrategias clave. En cuanto a la primera condición, esta está relacionada con la deconstrucción de nuestro propio adultocentrismo, lo que nos llevaba a estar constantemente revisando límites en cuanto a la proactividad. Había momentos en que las y los estudiantes necesitaban tomar decisiones y otros en que debíamos hacerlo nosotras. Por ejemplo, por un lado estudiantes que presentaban motivación con pensar el vestuario, que a veces pasaban gran parte de la clase consiguiéndose gorros, chaquetas, etc. Y, el por otro, estudiantes que llegaban con poca disposición y era necesario buscarles un lugar en el trabajo conjunto, con actividades como grabar videos de los avances de cada grupo para tener un registro.

Esto nos llevó a idear ciertas estrategias clave, como poner objetivos concretos por clase (vamos a llegar hasta esta parte de la canción hoy), la elección de la música para la dinámica inicial y final, diversas tareas en relación con el vestuario y, en ocasiones, recreos extras breves o ensayos al exterior para reactivar la motivación grupal. Si bien ello generó mucha dificultad en cuanto a la contención del grupo y que se desfigurara constantemente el formato de clase propuesto, también nos permitió priorizar el sentido de pertenencia a partir de estos ritos de inicio y cierre que, en conjunto con el ambiente dinámico de la sala, facilitaron la motivación y la colaboración que buscábamos como prioridad, cosa que no creíamos posible con ese grupo particular en un ambiente "controlado" de sala de clases.

En el tema del uso y la elección de las movilidades trabajadas se abren tanto el hito pedagógico de ampliar las posibilidades estilísticas fuera del reggaetón y las danzas tradicionales latinoamericanas que habían sido trabajadas hasta ese momento, como poner en práctica un camino pensado pero aún no aplicado: desbinarizar las danzas. Esta concepción de desbinarizar, en clave decolonial, no fue explicitada en ese entonces, se trata más bien de una lectura actual de cómo se desarrolló la praxis del taller, y la proponemos desde la

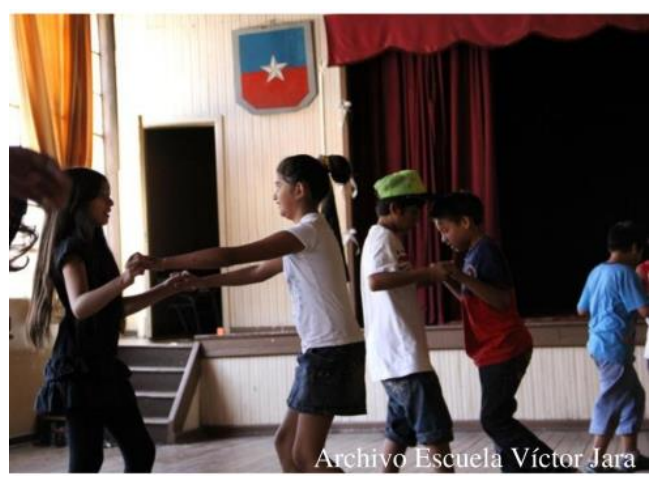
perspectiva intencionada de que ambos grupos fueran compuestos tanto por hombres, mujeres y otras definiciones, quienes se movían indistintamente, elemento que pretendía desbaratar los roles de género fuertemente presentes hasta ese momento en las danzas trabajadas.

El Taller Danza Grandes, desde estas perspectivas, nos permitió abrir un espacio particular y situado, en el que se asumió la práctica ejemplificada aquí como un apuesta móvil y que tensiona las ideas de tradición asociadas a la antiguiedad, propuesta quizás poco correcta y desobediente de ciertas formas de comprender la identidad y lo tradicional, pero que facilitan un ámbito propio de identificación entre los jóvenes y un diálogo entre sus biografías personales, colectivas y las opresiones vigentes vividas día a día. En las palabras de Milca Galea: "Cada testimonio personal, cada microhistoria, se encuentra en una unidad imperecedera, superando cualquier narrativa o escritura convencional, el territorio acoge, poniendo en valor la colectividad, para dar forma a las identidades territoriales y al sentido de pertenencia" (615). 


\section{Conclusiones}

Para concluir, nos proponemos aplicar, también, el espíritu crítico que hemos propiciado en este artículo. Somos conscientes de las falencias o los trabajos pendientes sobre nuestra práctica, que está lejos de ser completamente coherente y "exitosa", pero que fue emprendida desde el impulso de motivar caminos para todas y todos los que pulsan horizontes similares y buscan alimentar maneras de abordar la educación popular, la interculturalidad crítica y las danzas en la praxis misma. Por ello enfatizamos los aciertos y nuestra convicción para aportar insumos a esta necesidad de transformación colectiva. Dicho esto, expondremos tanto las vinculaciones logradas en el proceso como las tareas que faltan por cumplir, aspectos ambos directamente ligados a la idea de comprender que el ejercicio político-educativo del Taller Danza Grandes y de la Escuela Víctor Jara respondió a un contexto histórico particular desde el cual se deben leer las razones por las que se lograron estas vinculaciones como comprender las falencias que nos habitaron. Ambos elementos serán abordados tanto desde la observación de ciertas problemáticas como desde la estructura organizacional misma de la Escuela.

De forma general, independientemente de si fue una vinculación efectiva o un camino por desarrollar, concluimos que en la praxis del Taller Danza Grandes existió un diálogo entre la tríada conceptual de educación popular, interculturalidad crítica y danzas. A partir de esta afirmación abrimos, autocríticamente, las presentes conclusiones.

\section{Relaciones efectivas y tareas por cumplir}

Como primera relación efectiva en la aplicación de esta tríada conceptual al ejercicio del Taller Danza Grandes, nos encontramos con la concreción de un espacio de educación propia, particular y situada - que hoy leemos como decolonial- para abordar la realidad migratoria del Barrio Yungay a partir de la utilización de las artes, y en específico las danzas, como herramienta para esta práctica de autogobernanza educativa por fuera de los márgenes del currículum y la ideología de la escuela formal. Influenciadas por el proceso histórico de movilización estudiantil acaecido durante 2011, la Escuela Víctor Jara y el taller en cuestión lograron consolidarse bajo lógicas propias, construidas crítica y dialógicamente, potenciando así una segunda relación efectiva: las ideas de identidad, sentido de pertenencia y heterogeneidad, en un espacio que se alimenta de la diferencia, considerándola un valor sobre el cual crecer y construir, conscientes de que todas y todos quienes componen el taller (incluidas las educadoras) son jóvenes de diversas edades, territorios, culturas, etc. Este sentido de pertenencia e identidad lo vemos plasmado tanto en las creaciones coreográficas como en las metodologías y el ambiente de trabajo del taller, en los que dialogaban diversos intereses, lo que generó un espacio compuesto por la sumatoria de ideas, danzas, ritmos y propuestas que desembocaron en creaciones tan particulares como la fusión salseros-michael jacksons, donde todos los cuerpos, las biografías y las necesidades tenían cabida.

Esto nos lleva a la tercera relación efectiva entre esta tríada y la praxis misma: el cuerpo. Nuestra posición ha sido la de contemplarlo como un espacio de disputa desde la mirada decolonial, como el territorio donde toda esta praxis dialoga y acontece. Desde esa perspectiva, leemos como un acierto la decisión de utilizar las danzas como herramienta pedagógica decolonial, a partir de la propuesta de Viaña, Tapia y Walsh (78) de generar otras formas de ser, 
GONZÁLEZ PAULINA - Danza en la Escuela Víctor Jara: un análisis situado desde la Educación Popular, la interculturalidad crítica y los estudios de danzas

conocer y sentir distintas a las hegemónicas. Esto lo percibimos en la utilización de las danzas como herramienta educativa, una disciplina que pone en el centro de su práctica al cuerpo y que se sitúa, desde ahí, al servicio de un quehacer colectivo, constante y emancipador. En esa línea, también consideramos como un logro la diversidad plural de la concepción de danzas a través de instancias tales como la desarrollada con las y los michael jacksons y las y los salseros, que nos hablan de un ejercicio claro e intencionado de relevar otras danzas que tengan componentes motivantes e identitarios para las y los jóvenes, danzas que destaquen las formas propias de ver el mundo, de crear y aprender en comunidad.

Por otro lado, desde la perspectiva de la estructura general de la Escuela Víctor Jara y, con ello, de la lectura en conexión con el Taller Danza Grandes, identificamos como principal y sustancial la relación efectiva con lo dialógico (Freire 72) como materia prima para la configuración constante y crítica de este espacio político-educativo. Esta práctica, llevada a cabo de forma cotidiana y constante en las diversas instancias del proyecto, nos permitieron ir contextualizando, modificando y creciendo conjuntamente en la consolidación de este desde una mirada horizontal y en autogobernanza, pilares fundamentales para el desarrollo de la educación propia y situada en las danzas.

En cuanto a las tareas aún por cumplir y continuando con la mirada estructural y orgánica, proponemos la horizontalidad como una práctica que si bien es llevada a cabo y explicitada también en los postulados fundacionales de la Escuela y el taller, ${ }^{7}$ es una tarea aún por cumplir, pues exige constantes renovaciones y prácticas cotidianas que vayan de la mano con los horizontes trazados. Es necesario afinar críticamente el vínculo entre educadores, la forma en cómo se toman las decisiones y se hace circular la información dentro de la Escuela, y propiciar, a la vez, la revisión del vínculo educadores-educandos desde el fortalecimiento dialógico de la construcción de los programas, las metodologías y el trabajo en general.

Retomamos aquí la necesidad de entender el proyecto Escuela Víctor Jara dentro de un momento histórico particular, con sus respectivas fortalezas y debilidades. Si consideramos el proceso gatillado en Chile a partir de la revuelta popular del 18 de octubre de 2019, sumado a las grandes movilizaciones feministas desarrolladas tanto en Chile como en otros países durante los últimos años, se hace ineludible y necesario observar la práctica de la Escuela Víctor Jara desde este contexto presente, con un prisma crítico en cuanto a la perspectiva de género. En esta línea, el trabajo realizado aparece como un camino no resuelto y pendiente en cuanto a desarrollar un abordaje directo, aplicado y crítico sobre el género en la práctica artística, política y pedagógica del Taller Danza Grandes y de toda la Escuela Víctor Jara.

Atisbamos esta idea abriendo un camino hacia la desbinarización de las danzas, pero fue un esfuerzo localizado, particular e insuficiente para una problemática que debe ser abordada de forma global y sostenida tanto por el taller como por el proyecto total de la Escuela. Tal esfuerzo no solo debe enfrentarse desde el tratamiento binario, sino intentando permear la perspectiva de género en todos los espacios de la Escuela: en la forma en que se elaboran los programas, en cómo se median e intensionan las dinámicas relacionales dentro del proyecto, etc., es decir, no solo enunciando sino practicando otras formas posibles, desde una reflexión y praxis que contemple las opresiones de género vinculadas con todos los demás sistemas de opresión

\footnotetext{
${ }^{7}$ Para más información revisar Monreal.
} 
imbricados (clase, raza y edad). Ello instala cuestionamientos también hacia nuestros referentes danzarios y cómo se manifiestan en ellos las problemáticas de género, sobre todo en ritmos que aparecen de forma cotidiana en el taller y la Escuela, como es el caso del reggaetón y la bachata.

En este ejercicio crítico de lectura posterior, aparece también el cuestionamiento directo a la figura de Michael Jackson, que, si bien es un referente importante y motivante tanto para las y los jóvenes del taller como para otras generaciones, también es un conocido pedófilo. Abordar tales contradicciones, sin ánimos de una prohibición a priori, sino más bien buscando asumir, observar e instalar la crítica desde esta contradicción, son actitudes que quedan aún por pensar y practicar de forma colectiva para abrir camino hacia otros referentes posibles desde una mirada de clase, raza, género y edad.

Desde el ejemplo de Michael Jackson surge también la necesidad de explicitar un trabajo más claro y crítico sobre las problemáticas de identidad y racialización, sobre todo desde la perspectiva de $\mathrm{raza}^{8}{ }^{8}$ que contemple sus efectos opresivos y estructurales y cómo estos operan en los cuerpos racializados. Por ejemplo, en el caso mencionado, tensionando a un referente negro que decide blanquearse la piel, ya que, al contemplar de manera situada el taller y la Escuela, vemos que se trata de espacios compuestos en su mayoría por jóvenes de color. ${ }^{9}$

Con base en ello cabe preguntarse qué otros referentes de color podemos encontrar en las danzas. ¿Cómo podemos abordar las danzas y su proceso de enseñanza-aprendizaje con perspectiva de género? ¿Qué reflexiones y acciones podemos emprender desde estos cuestionamientos? Queda, entonces, como tarea pendiente y necesaria, el abordaje directo de las perspectivas de género y racial-identitaria a partir de una profundización de la lectura sistémica de su vínculo con las ideas de clase, edad y las múltiples opresiones que comenzamos a visualizar desde la mirada de la interculturalidad crítica y, a su vez, cómo estas se desarrollan por medio de las danzas mediadas en un ejercicio político y colectivo como es la educación popular.

Todas estas posibilidades, tanto las desarrolladas como las aún por cumplir, son posibles gracias al ejercicio del ensayo-error y sus respectivas evaluaciones críticas y colectivas, que nos invitan a proponer metodologías y otros caminos posibles. Todo aquello, finalmente, configura la experiencia situada del Taller Danza Grandes de la Escuela Víctor Jara y los aprendizajes que de esta se desprenden.

Creemos que el presente artículo de análisis teórico de esta experiencia particular puede aportar al campo de la pedagogía crítica en danza y, con ello, a futuros proyectos que se piensen con un horizonte decolonial desde la educación popular, la interculturalidad crítica y las danzas en espacios que se propongan trabajar en territorios con jóvenes que vivencian la realidad migratoria latinoamericana. Pretende ser un insumo para posibles nuevas construcciones que busquen encarnar y actuar las transformaciones y los horizontes que queremos ver concretados, motivando con ello, a su vez, a que existan cada vez más espacios orientados al trabajo crítico por

\footnotetext{
${ }^{8}$ Con Quijano nos aproximamos a "la idea de raza, es decir, una supuesta diferente estructura biológica que ubicaba a los unos en situación natural de inferioridad respecto de los otros. Esa idea fue asumida por los conquistadores como el principal elemento constitutivo, fundante, de las relaciones de dominación que la conquista imponía" (202).

9 Nos referimos a la concepción de color de María Lugones: "Las feministas de color nos hemos movido conceptualmente hacia un análisis que enfatiza la intersección de las categorías raza y género porque las categorías invisibilizan a quienes somos dominadas y victimizadas bajo la categoría 'mujer' y bajo las categorías raciales 'Black', 'hispanic', 'Asian', 'Native American', 'Chicana' a la vez, es decir a las mujeres de color (81-82).
} 
GONZÁLEZ PAULINA - Danza en la Escuela Víctor Jara: un análisis situado desde la Educación Popular, la interculturalidad crítica y los estudios de danzas

y para este Sur global, por y para las niñas, los niños y los jóvenes de este territorio común como un ejercicio necesario, colectivo y decolonizador. 


\section{Bibliografía}

Arce, Alena, Omar Campos, Constanza S. Gómez y Celeste González. MOV 360: Práctica en el cuerpo y teoría para la danza contemporánea desde el territorio sudamericano. Santiago: Ministerio de las Culturas, las Artes y el Patrimonio, 2018. Impreso

Baronnet, Bruno. "El movimiento zapatista y la educación para la autonomía". Pedagogías insumisas, movimientos político-pedagógicos y memorias colectivas de educaciones otras en América Latina. Patricia Medina Melgarejo (coord.). San Cristóbal de las Casas: Universidad de Ciencias y Artes de Chiapas, Centro de Estudios Superiores de México y Centroamérica, Educación para las Ciencias en Chiapas, Juan Pablos, 2015. Impreso

Bastide, Roger. Las Américas negras: Las civilizaciones africanas en el Nuevo Mundo. Madrid: Alianza, 1969. Impreso

Beniscelli, Leonora, Andrea Riedemann y Fernanda Stang. "Multicultural, y sin embargo asimilacionista: Paradojas provocadas por el currículo oculto en una escuela con alto porcentaje de alumnos migrantes". Calidad en la Educación 50 (2019): 393-423. Web. 1 oct. 2020

Colectivo Miradas Críticas del Territorio desde el Feminismo. Mapeando el cuerpo-territorio: Guía metodológica para mujeres que defienden sus territorios. Quito: Colectivo Miradas Críticas del Territorio desde el Feminismo, Red Latinoamericana de Defensoras de Derechos Sociales y Ambientales, Instituto de Estudios Ecologistas del Tercer MundoCLACSO, 2017. Impreso.

Duarte, Klaudio. "Genealogía del adultocentrismo: La constitución de un patriarcado adultocéntrico". Juventudes en Chile: Mirada de jóvenes que investigan. Klaudio Duarte \& Carolina Álvarez (eds.). Santiago: Facultad de Ciencias Sociales, Universidad de Chile, 2016. Impreso.

El Rincón Boliviano. "Tinkus, danza, música y vestimenta". Web. 20 oct. 2020. https://elrinconboliviano.com/danzas-de-bolivia/danza-tinku/.

Freire, Paulo. Pedagogía del oprimido. Buenos Aires: Tierra Nueva, 1970. Impreso

Galea, Milca. "Extractos de un cuerpo chango". El libro de la danza chilena: La danza se escribe a sí misma. Poly Rodríguez, Marcela Olate e Ignacio Vargas (eds.). Santiago: Ministerio de las Artes, las Culturas y el Patrimonio, 2019. Impreso.

García, Jorge. "Educación propia, educación liberadora o pedagogía de la desobediencia en las comunidades afro del Pacífico sur colombiano". Pedagogías insumisas, movimientos político-pedagógicos y memorias colectivas de educaciones otras en América Latina. Patricia Medina Melgarejo (coord.). San Cristóbal de las Casas: Universidad de Ciencias y Artes de Chiapas, Centro de Estudios Superiores de México y Centroamérica, Educación para las Ciencias en Chiapas, Juan Pablos, 2015. Impreso. 
GONZÁLEZ PAULINA - Danza en la Escuela Víctor Jara: un análisis situado desde la Educación Popular, la interculturalidad crítica y los estudios de danzas

González, Paulina. "Danzas, Educación popular e Interculturalidad crítica en el Taller Danza Grandes de la Escuela Víctor Jara" Tesis. Universidad ARCIS. 2020. Impreso

Gutiérrez, Raquel. ;A desordenar! Por una historia abierta de la lucha social. Buenos Aires: Tinta Limón, 2016. Impreso.

Guzmán, Adriana. Descolonizar la memoria, descolonizar los feminismos. La Paz: Tarpuna Muya, 2019. Impreso.

Lander, Edgardo y Santiago Castro-Gómez. La colonialidad del saber: Eurocentrismo y ciencias sociales: Perspectivas latinoamericanas. Buenos Aires: Consejo Latinoamericano de Ciencias Sociales (CLACSO), 2000. Impreso.

Lanka, Cata y Gabriel Morales. "Pachallampe (ritual aymara de la siembra de la papa)".

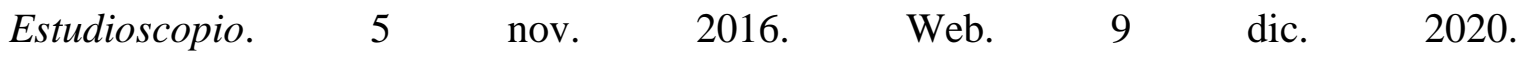
https://estudioscopio.bandcamp.com/album/pachallampe-ritual-aymara-de-la-siembra-dela-papa.

Lugones, María. “Colonialidad y género”. Tabula Rasa 9 (2008): 73-101. Web. 10 jul. 2020. https://www.revistatabularasa.org/numero09/colonialidad-y-genero/.

Maldonado-Torres, Nelson. "Sobre la colonialidad del ser: Contribuciones al desarrollo de un concepto". El giro decolonial: Reflexiones para una diversidad epistémica más allá del capitalismo global. Santiago Castro-Gómez y Ramón Grosfoguel (comp.). Bogotá: Siglo del Hombre, Universidad Central, Instituto de Estudios Sociales Contemporáneos, Pontificia Universidad Javeriana, Instituto Pensar, 2007. 127-167. Impreso.

Monreal, José. "Escuelita Víctor Jara". 23 sep. 2015. Web. 15 nov. 2020. https://prezi.com/skh5krsr2yp/escuelita-victor-jara/.

Nohl, Arnd-Michael. Konzepte interkultureller Pädagogik. Eine systematische Einführung. Alemania: AZ Druck und Datentechnik, Kempten. 2014. Impreso

Preiswerk, Matthias. "Raíces y plataformas de la educación popular”. ¿Qué es la educación popular? Martha Delgado, María Isabel Romero y José Vidal (comps.). La Habana: Caminos, 2012. Impreso.

Quijano, Aníbal. Colonialidad del poder, eurocentrismo y América Latina. La colonialidad del saber: Eurocentrismo y ciencias sociales: Perspectivas latinoamericanas. Edgardo Lander y Santiago Castro-Gómez (coords.). Buenos Aires: Consejo Latinoamericano de Ciencias Sociales-CLACSO, 2000. Impreso

Rolnik, Suely. Esferas de la insurrección: Apuntes para descolonizar el inconsciente. Buenos Aires: Tinta Limón, 2019. Impreso.

Sigl, Eveline y David Mendoza. No se baila así no más... Género, poder, etnicidad, clase, religión y biodiversidad en las danzas del altiplano boliviano (Tomo I). La Paz: Sin editorial, 2012. Impreso. 
Tijoux, María Emilia. "El cuerpo como cicatriz: Relaciones coloniales y violencia racista". Conferencia magistral. Décimo Encuentro del Instituto Hemisférico de Performance y Política, Universidad de Chile. 18 jul. 2016. Web. 1 oct. 2020.

Viaña, Jorge, Luis Tapia y Catherine Walsh. Interculturalidad crítica y educación intercultural: Construyendo interculturalidad crítica. La Paz: Instituto Internacional de Integración del Convenio Andrés Bello, 2010. Impreso.

Recibido: 26 de Abril de 2021

Aceptado: 03 de Julio de 2021 